\title{
Acesso ao ensino superior brasileiro: perfil dos ingressantes do programa de inclusão da Unicamp
}

\author{
The access to the Brazilian higher education: analysis of the profile of beneficiaries the \\ program of social inclusion in the Unicamp
}

\author{
André Pires* \\ Bruna Mara da Silva Wargas*
}

\section{Resumo}

As políticas de acesso ao ensino superior brasileiro, nos últimos 15 anos, mudaram a composição da população brasileira que acessou as universidades públicas e privadas. O presente artigo analisa o perfil dos ingressantes por meio de um dos programas de acesso no âmbito da Universidade Estadual de Campinas (Unicamp). O acesso à universidade foi modificado com a criação do Programa de Ação Afirmativa e Inclusão Social em 2004, que incentiva o acesso dos estudantes da rede pública de ensino (EP), bem como de estudantes autodeclarados pretos, pardos ou indígenas (PPI), com a adição de pontos à nota desses candidatos no vestibular. O método utilizado foi uma pesquisa documental em bases primárias e secundárias, pautada em pesquisa bibliográfica sobre políticas públicas de acesso ao ensino superior, além de análise de dados do período de 2005 a 2018 , disponíveis nas páginas eletrônicas da universidade. Como resultado, observa-se que a política apresenta dois momentos distintos, o primeiro, até 2013 , com uma modificação tímida na composição dos ingressantes EP e PPI, e o segundo, de 2014 até a realização deste estudo, com uma elevação no número de ingressantes provenientes de EP, alcançando o percentual de 50\% dos ingressantes em 2017, em contraste com o ano de 2005, quando o percentual foi de $28 \%$. Com relação aos estudantes PPI, o índice passou de 12\%, em 2005, para 24\%, em 2018, número que deverá crescer nos próximos anos, pois a universidade aprovou o programa de cotas étnico-raciais que será implementado a partir de 2019. Apesar dos números favoráveis, o artigo discute os desafios colocados à universidade para criar condições de permanência para jovens de famílias pobres de primeira geração no ensino superior.

Palavras-chave: Ações afirmativas. Ensino superior. Políticas públicas.

Recebido em 08/07/2018 - Aprovado em 04/10/2018

http://dx.doi.org/10.5335/rep.v26i1.8367

Doutor em Ciências Sociais pela Universidade Estadual de Campinas (Unicamp). Professor do Programa de Pós-Graduação em Educação na Pontifícia Universidade Católica de Campinas (PUC-Campinas). E-mail: anpires@gmail.com Mestre em Economia pela Universidade Estadual Paulista (Unesp). Doutoranda em Educação na PUC-Campinas. E-mail: brunamarawargas@yahoo.com.br 


\section{Abstract}

Public policies for access to students from poor families in Brazilian higher education in the last 15 years have changed the composition of public and private universities. The present study analyzes the profile of these students through one of the poor students' access programs to the State University of Campinas (Unicamp). The Affirmative Action and Social Inclusion Program (PAAIS), created in 2004, aims to promote inclusion of students graduating from the public high school system, as well as self-declared black or indigenous. The research method consisted in documental analyses on primary and secondary bases, based in bibliographical research on public policies on access to higher education and analyzing the data from the period 2005 to 2018 , available in the statistical yearbook of the university. As a result, there was two moments, the first time until 2013 with a minor change. The second time observed an increase in the number of students coming from public high schools, reaching $50 \%$ of the number of freshmen in 2017 , compared to $28 \%$ in 2005 . There was also an increase in the number of black or Indian students: from $12 \%$ in 2005 to $24 \%$ in 2018, a number that is expected to grow in the coming years, because the University has been approved a program of ethnic-racial quotas that will be implemented from 2019. Despite the favorable numbers, the article discusses the challenges posed to the University to create conditions of permanence for young people from poor families first generation in University.

Keywords: Affirmative actions. Higher education. Public policies.

\section{Introdução}

Com a modernização da sociedade, associada ao desenvolvimento de um sistema produtivo baseado na capacidade de suscitar novas tecnologias, é necessário que uma parcela da população tenha a qualificação adequada para atuar em complexas organizações (DURHAM; GOLDEMBERG, 1993).

De acordo com Schofer e Meyer (2005), muitos países, após os anos 1960, passaram por elevado crescimento no ensino superior em decorrência da necessidade de capital humano especializado para atender à demanda da economia mundial, que vivenciava um período de expansão e modificação de suas estruturas produtivas.

Nos anos 2000, de acordo com dados do Ministério da Educação (BRASIL, 2012c), a parcela total da população brasileira com ensino superior completo era de 4,4\%, em torno de 6,1 milhões, percentual que aumentou, em 2010, para 7,9\%, alcançando 12,8 milhões. No entanto, esse patamar é bastante reduzido se compararmos com outros países da própria América Latina, como a Colômbia, que tem $22 \%$, e o Chile, com 21\%, de acordo com dados da Organização para Cooperação e Desenvolvimento Econômico (2016).

A inserção da população brasileira no ensino superior apresenta, ao longo da história, percentuais baixos, em especial, no que se refere à população mais pobre. Conforme Cibele Andrade (2012), o percentual da população entre 18 e 24 anos que, em 1995, acessou o ensino superior e estava no quintil ( $1^{\circ}$ quintil) mais baixo da renda foi de menos de $1 \%$, em torno de 14 mil estudantes, enquanto que, no 
quintil mais alto ( $5^{\circ}$ quintil), esse percentual foi de $23 \%$, cerca de 1 milhão de estudantes.

As políticas sociais realizadas pelo Estado brasileiro, ao longo dos anos 2000, levaram a um aumento na inserção dos jovens de renda mais baixa no ensino superior. Nas universidades públicas, isso ocorreu principalmente por meio do estabelecimento de cotas raciais (BRASIL, 2012a) e programas de inclusão para alunos egressos de escolas públicas. Nas universidades privadas, esse aumento foi devido à oferta de bolsas de estudos, do Programa Universidade para Todos (Prouni), e por meio do financiamento dos estudos com taxas de juros subsidiadas via Fundo de Financiamento Estudantil (Fies).

Diante desse conjunto de políticas públicas inserido no contexto brasileiro nos anos 2000, o presente trabalho realiza uma análise do Programa de Ação Afirmativa e Inclusão Social (Paais), instituído em 2004 na Universidade Estadual de Campinas (Unicamp), que visa proporcionar um maior acesso à universidade por estudantes egressos de escolas públicas. Para tal análise, foram avaliados os dados disponíveis no site da Comissão Permanente para os Vestibulares da Unicamp (Comvest), bem como trabalhos publicados que versam sobre o assunto.

O presente texto divide-se em quatro partes, a saber: evolução do ensino superior no país, apresentação da política de inclusão (Paais), análise do perfil dos alunos ingressantes no período 2004-2018 e das perspectivas das políticas de inclusão da universidade para 2019, a partir do estabelecimento das cotas étnico-raciais.

\section{Ensino superior no país}

No Brasil, a expansão do ensino superior nos 1970 foi impulsionada pela reforma de 1968, que plasmou o modelo a orientar a política do Estado brasileiro para esse segmento educacional. Em linhas gerais, as diretrizes são: ensino público gratuito, associação entre o ensino e a pesquisa e configuração organizacional preferencial em universidades. O setor privado se organizou em faculdades e centros universitários com foco no ensino (DURHAM, 1998; MARTINS, 2009).

$\mathrm{O}$ resultado da reforma e os investimentos governamentais levaram ao crescimento no número de matrículas nos cursos de graduação de 95.700, em 1960, para 425.500, em 1970, e 1.377.286, em 1980. As vagas no setor público (estadual e federal) aumentaram de 53.600 para 210.600 , entre 1960 e 1970, e atingiram 492.232, em 1980 (DURHAM, 1998).

O modelo escolhido para a seleção dos candidatos ao ensino superior por meio de exame de seleção (vestibular) e o número insuficiente de vagas no setor público, apesar da grande expansão entre os anos 1960 e 1980, geraram uma oportunidade 
de crescimento para o setor privado, que, já no início dos anos 1980, havia ultrapassado o setor público no total de matrículas: setor privado com 885.054 frente a 492.232 do setor público (DURHAM, 1998).

A discussão com relação à expansão do ensino superior no país se pautou em uma dualidade, na qual o setor privado logrou grande expansão e, na concepção de autores como Sampaio (2000), gerou um processo de massificação no número de matrículas. Nesse mesmo cenário, as universidades públicas se delinearam como as provedoras de ensino, pesquisa e extensão, fomentadas pelo Conselho Nacional de Desenvolvimento Científico e Tecnológico (CNPq) e pela Coordenação de Aperfeiçoamento de Pessoal de Nível Superior (Capes).

Até o início dos anos 1980, as estruturas das universidades públicas receberam grandes investimentos, foram construídos laboratórios de pesquisa e estruturados os cursos de pós-graduação e as políticas de fomento e incentivo à pesquisa, bem como os mecanismos de avaliação. Entretanto, com a crise do setor público no começo dessa década e a mudança no foco das políticas macroeconômicas a partir das exigências estabelecidas pelo Fundo Monetário Internacional para a concessão dos empréstimos destinados a sanear as contas públicas, assim como dos desdobramentos nos anos 1990, com a implantação de políticas de austeridade fiscal, os investimentos foram reduzidos (OLIVEIRA, 2006).

Nos anos 1990, nota-se grande expansão do número de vagas ofertadas no setor privado, de acordo com a Tabela 1. Observando-se o período de 1991 a 2000, houve um crescimento de $174 \%$, de 354.157 para 970.655 vagas, ao passo que, no setor público, o crescimento foi de 51\%, passando de 162.506 para 245.632 vagas.

Tabela 1 - Censo do ensino superior com número de vagas ofertadas por tipo de estabelecimento (1991-2015)

\begin{tabular}{c|c|c|c|c|c}
\hline \multicolumn{5}{c}{ Vagas ofe recidas Ensino Superior (INEP-MEC- CENSO 1991-2015) } \\
\hline \multirow{2}{*}{ Ano } & \multicolumn{3}{|c|}{ Ins tituições públicas } & \multirow{2}{*}{ TOTAL } & $\begin{array}{c}\text { Instituições } \\
\text { privadas }\end{array}$ \\
\cline { 2 - 4 } & Federal & Es tadual & Municipal & $\mathbf{1 6 2 . 5 0 6}$ & 354.157 \\
\hline 1991 & $\mathbf{7 8 . 5 0 2}$ & $\mathbf{5 3 . 3 1 3}$ & $\mathbf{3 0 . 6 9 1}$ & $\mathbf{1 7 8 . 1 4 5}$ & $\mathbf{4 3 2 . 2 1 0}$ \\
\hline 1995 & $\mathbf{8 4 . 8 1 4}$ & $\mathbf{6 1 . 3 5 2}$ & $\mathbf{3 1 . 9 7 9}$ & $\mathbf{1 7 8 . 1 4}$ & $\mathbf{9 7 0 . 6 5 5}$ \\
\hline 2000 & $\mathbf{1 2 0 . 4 8 6}$ & $\mathbf{9 6 . 1 7 9}$ & $\mathbf{2 8 . 9 6 7}$ & $\mathbf{2 4 5 . 6 3 2}$ & $\mathbf{2 . 1 2 2 . 6 1 9}$ \\
\hline 2005 & $\mathbf{1 2 7 . 3 3 4}$ & $\mathbf{1 2 8 . 9 4 8}$ & $\mathbf{5 7 . 0 8 6}$ & $\mathbf{3 1 3 . 3 6 8}$ & $\mathbf{2 . 3 6}$ \\
\hline 2010 & $\mathbf{2 4 8 . 5 3 4}$ & $\mathbf{1 3 8 . 3 1 8}$ & $\mathbf{5 8 . 4 8 5}$ & $\mathbf{4 4 5 . 3 3 7}$ & $\mathbf{2 . 6 7 4 . 8 5 5}$ \\
\hline 2015 & $\mathbf{3 2 9 . 5 6 4}$ & $\mathbf{1 7 5 . 6 8 7}$ & $\mathbf{6 6 . 6 4 3}$ & $\mathbf{5 7 1 . 8 9 4}$ & $\mathbf{5 . 5 7 0 . 2 5 5}$ \\
\hline $\begin{array}{c}\% \\
\text { Crescimento } \\
1991-2000\end{array}$ & $\mathbf{5 3} \%$ & $\mathbf{8 0} \%$ & $-6 \%$ & $\mathbf{5 1 \%}$ & $\mathbf{1 7 4 \%}$ \\
\hline $\begin{array}{c}\% \\
\text { Crescimento } \\
2000-2015\end{array}$ & $\mathbf{2 7 4} \%$ & $\mathbf{1 8 3} \%$ & $\mathbf{2 3 0} \%$ & $\mathbf{2 3 3} \%$ & $\mathbf{5 7 4} \%$ \\
\hline
\end{tabular}

Fonte: elaboração própria com dados do Censo (BRASIL, 2016). 
Entretanto, apesar da ocorrência de expansão do número de vagas e matrículas no ensino superior brasileiro, o acesso às universidades não teve na equidade o seu ponto mais relevante. O ingresso, até a década de 2000, esteve voltado ou mais disponível à população com melhores condições econômicas. Ponto auge dessa questão é que as universidades públicas não levavam em consideração a condição econômica do estudante no momento da seleção. De acordo com Durham,

Até pelo contrário, os vestibulares, nas universidades públicas gratuitas, por serem os mais disputados e competitivos, privilegiam indiretamente os estudantes mais abastados, cujas famílias foram capazes de realizar um investimento financeiro elevado na sua formação anterior. Além do mais, a escassez de cursos noturnos nos estabelecimentos públicos faz com que a população que trabalha se encaminhe para o ensino privado (1998, p. 13).

A expansão das matrículas no ensino superior, nos anos 2000, foi acompanhada por políticas de ações afirmativas para a inclusão de grupos historicamente excluídos do ensino superior. Esse conjunto de políticas, na visão de Almeida e Ernica, "[...] representa um esforço, sem precedentes, para diminuir os efeitos de privilégios sociais nos processos de acesso ao ensino superior no país" (2015, p. 64).

A partir dos anos 2000, uma série de políticas estabelecidas pelo governo federal retomou o estímulo da expansão do número de vagas nas universidades federais, assim como no setor privado, consolidando-se, dessa forma, o objetivo de ampliar a inclusão das camadas mais pobres da sociedade.

As três principais políticas federais nesse âmbito são: o Programa de Apoio a Planos de Reestruturação e Expansão das Universidades Federais (Reuni), estabelecido em 2007, que tem o objetivo de criar condições para a ampliação do acesso e da permanência na educação superior, no nível de graduação, pelo melhor aproveitamento da estrutura física e de recursos humanos existentes nas universidades federais; o Prouni, criado em 2005, que disponibiliza bolsas de estudos integrais e parciais em estabelecimentos privados; e o Fies, instituído em 2001, que proporciona financiamento de crédito estudantil a taxas de juros subsidiados.

Nesse contexto de retomada do olhar do setor público para o ensino superior brasileiro, o número de universidades públicas e privadas cresceu, bem como o número de matrículas. Em 2015, 88\% dos estabelecimentos eram privados, e 12\%, públicos, detendo $73 \%$ e $27 \%$ das matrículas, respectivamente, conforme dados da Tabela 2. No período entre 2000 e 2015, o número de matrículas do setor privado cresceu 166\%, e o número de instituições de ensino superior (IES), 106\%. Em relação ao setor público, o número de matrículas cresceu $105 \%$, e o de instituições, $67 \%$. O crescimento mais surpreendente do período foi o do número de vagas oferecidas. Retornando à Tabela 1 , o setor privado aumentou sua oferta em $574 \%$, ante $230 \%$ do setor público. Os dados demonstram que o investimento do setor público logrou êxito no objetivo de expandir o ensino superior no país. 
Tabela 2 - Censo do ensino superior com número de instituições públicas e privadas e matrículas (2000-2015)

\begin{tabular}{|c|c|c|c|c|c|}
\hline Ano & $\mathbf{2 0 0 0}$ & $\mathbf{2 0 0 5}$ & $\mathbf{2 0 1 0}$ & $\mathbf{2 0 1 5}$ & $\%$ \\
\hline Número de IES & 1.180 & 2.165 & 2.378 & 2.364 & \\
\hline Privada & 1.004 & 1.934 & 2.100 & 2.069 & $88 \%$ \\
Pública & 176 & 231 & 278 & 295 & $12 \%$ \\
\hline Número de matrículas & 2.694 .245 & 4.453 .156 & 5.449 .120 & 6.633 .545 & \\
\hline Privada & 1.807 .219 & 3.260 .967 & 3.987 .424 & 4.809 .793 & $73 \%$ \\
\hline Pública & 887.026 & 1.192 .189 & 1.461 .696 & 1.823 .752 & $27 \%$ \\
\hline
\end{tabular}

Fonte: elaboração própria com dados da Comvest (UNICAMP, 2018a).

De acordo com Ristoff (2016), as políticas implementadas a partir dos anos 2000 modificaram o ensino superior brasileiro, o Reuni melhorou a estrutura física das universidades federais, aumentou o número de vagas, novos campi foram implantados, novos cursos foram criados e, com isso, novas vagas foram geradas para docentes e corpo técnico-administrativo, além de mais oportunidades para os estudantes do interior do país. Por sua vez, o Prouni também gerou uma grande transformação, segundo os dados do Ministério da Educação (BRASIL, 2018), os quais apontam que quase dois milhões de estudantes foram beneficiados, desde 2005, em que pesem as críticas tecidas pelo próprio Ristoff (2016), apontando o custo do programa, a qualidade e os interesses envolvidos com relação às instituições privadas: “[...] é possível afirmar que o Prouni reúne três dos ingredientes básicos da boa política pública: inclusão, qualidade e baixo custo" (2016, p. 22).

Dentro desse movimento ocorrido nos anos 2000, uma questão emerge e pauta a análise das políticas públicas: a inserção da camada mais pobre da população e que, historicamente, apresenta baixos percentuais de acesso ao ensino superior. Várias discussões surgiram nesse contexto, colocando, por exemplo, a questão de cotas raciais, sociais e programas de inclusão social nas universidades públicas. Algumas instituições, como a Universidade Estadual do Rio de Janeiro (Uerj), em 2001, e a Universidade de Brasília (UnB), em 2003, foram pioneiras no estabelecimento de cotas no país. No entanto, o decreto federal que institui como obrigatoriedade a reserva de $50 \%$ das vagas para estudantes provenientes de escolas públicas e com baixa renda foi publicado apenas em 2012 (BRASIL, 2012a). De acordo com Schwartzman:

Em 2012, o Supremo Tribunal Federal declarou que as cotas raciais eram constitucionais; no mesmo ano, o Congresso aprovou a legislação que exige que $50 \%$ das vagas em universidades públicas sejam reservadas a estudantes oriundos de escolas públicas, dando preferência a não brancos. Além disso, entre 2008 e 2011, o número de admissões nas Universidades Federais aumentou 50\% (2015, p. 284). 
Heringer (2014) também chama atenção para a importância da decisão do Supremo Tribunal Federal. Em suas palavras,

[...] tal resultado trouxe segurança jurídica às práticas que vinham sendo implementadas por centenas de instituições em todo país, levando também a uma legitimação do ponto de vista não apenas jurídico, mas também político e ideológico sobre a justeza e relevância das políticas de ação afirmativa (2014, p. 23).

Vários são os pontos de vista sobre a temática das ações afirmativas no ensino superior brasileiro. Os defensores apontam que o desempenho dos estudantes beneficiados é igual ou superior ao dos demais estudantes (VELLOSO, 2006, 2009), enquanto algumas pesquisas recentes, como a de Wainer e Melguizo (2018), demonstram, a partir dos dados do Exame Nacional de Desempenho de Estudantes (Enade), que o desempenho de estudantes cotistas beneficiados pelo Fies é igual ao de estudantes não beneficiados pelas políticas, assim como os estudantes que receberam bolsas do Prouni têm desempenho superior.

Não há diferença prática entre o conhecimento de alunos cotistas e o de seus colegas de classes não cotistas ao final do curso, se assumirmos que o exame do Enade mede tanto habilidades gerais de raciocínio como conhecimentos específicos do curso. Não há diferença prática entre o conhecimento de alunos cotistas por razões raciais ou sociais e o de seus colegas de classes que não são cotistas. Não há diferença prática de conhecimentos entre cotistas e não cotistas em classes com média alta nos exames de conhecimento específico. Também não há diferença prática de conhecimento ao final da graduação entre alunos que receberam empréstimo pelo Fies e seus colegas de classe que não receberam o empréstimo. Finalmente, alunos que receberam bolsa do ProUni parecem ter acumulado mais conhecimentos que seus colegas de classes (WAINER; MELGUIZO, 2018, p. 13).

Os críticos, como exposto por Schwartzman, inferem que "[...] os cursos estão sendo forçados a baixar seus padrões acadêmicos, e que o uso oficial da raça na política pública vai contra os princípios constitucionais contra a discriminação" (2015, p. 284).

Dessa forma, várias universidades pelo país passaram a adotar mecanismos para inclusão social em seus processos de seleção, seja por meio de cotas raciais e sociais ou de programas de ação afirmativa, como no caso da Unicamp, foco deste trabalho, onde a política se pauta na adição de pontos à nota dos candidatos no processo de seleção pelo vestibular.

\section{Metodologia da pesquisa}

O método utilizado para a realização do presente trabalho partiu de uma pesquisa documental e da revisão de literatura. De acordo com Marconi e Lakatos (2003), a pesquisa documental pode consistir em análise de fontes primárias, no 
caso, a análise de uma determinada base de dados disponível, e na revisão de literatura, que se refere às fontes secundárias. A pesquisa documental objetiva organizar informações para compreender determinadas circunstâncias que se estão investigando.

No caso da pesquisa em questão, os documentos estão em bases públicas e foram compilados para traçar o perfil dos ingressantes pela política pública da universidade. Além disso, foi procedida à pesquisa bibliográfica de textos que abordam a temática e apresentam análises de seus efeitos e/ou resultados, complementada pela busca dos documentos relativos à criação do programa.

Para o levantamento da bibliografia, foi realizada uma pesquisa nas bases de dados SciELO e Biblioteca Digital Brasileira de Teses e Dissertações (BDTD), com os descritores Paais e Programa de Ação Afirmativa e Inclusão Social, mediante a qual se encontrou apenas uma dissertação de mestrado de 2015, intitulada Análise do Programa de Ação Afirmativa e Inclusão Social (Paais) implementado pela Unicamp no período de 2005-2014, de Fritznel Alphonse (2015).

No intuito de encontrar mais documentos que tratam do assunto, a pesquisa se estendeu ao Google Acadêmico e às páginas eletrônicas da universidade, empregando os mesmos descritores. Com esse procedimento, obteve-se um artigo publicado em 2008, com o título Paais: a experiência de um programa de ação afirmativa na Unicamp, de Leandro Tessler e Renato Pedrosa (2008), algumas notas técnicas no site da Comissão de Vestibulares da universidade, que abordam o vestibular e a política do Paais, como Vestibular Unicamp e a inclusão social: experiências e perspectivas, além da portaria de criação e das respectivas alterações do programa.

Os dados analisados consistem nos documentos disponibilizados no site da Comvest, no qual constam os dados absolutos com relação ao perfil dos ingressantes, baseado no questionário socioeconômico preenchido no momento da inscrição no vestibular. Vale ressaltar que a universidade disponibiliza a série histórica desde o vestibular de 1987.

O intervalo selecionado como amostra compreende todo o período de implementação do programa, de 2005 a 2018, e em especial duas modificações na configuração do Paais, em 2014 e 2016.

\section{Programa de Ação Afirmativa e Inclusão Social da Unicamp}

Estabelecido em 2004 pela Deliberação no 12, de 2004, do Conselho Universitário da Unicamp, o Paais tem por objetivo estimular o ingresso, nessa universidade, de estudantes da rede pública de ensino e de estudantes autodeclarados pretos, pardos ou indígenas, com a adição de pontos à nota final desses candidatos 
no vestibular. O primeiro vestibular de vigência do projeto ocorreu no ano de 2005 , quando o percentual de ingressantes pelo programa foi de $32,9 \%$ do total de matriculados (UNICAMP, 2017).

Para o estabelecimento do programa, foram realizados vários estudos na universidade sobre questões de inclusão, cotas ou reserva de vagas e desempenho acadêmico. Levou-se em consideração que, entre estudantes com notas semelhantes no vestibular, aqueles que cursaram o ensino médio em escolas públicas apresentaram, ao longo do curso, uma variação do desempenho acadêmico positiva e superior em relação aos demais, de acordo com Tessler:

O resultado desse estudo indicou que, se a Unicamp de alguma forma aumentasse o número de egressos de escolas públicas entre seus alunos, o resultado poderia ser positivo em termos de desempenho acadêmico. Isso pode ser entendido da seguinte forma: se dois candidatos, um egresso de escola pública e um de escola privada empataram (tiveram pontuação semelhante) no vestibular, se optarmos pelo que veio da escola pública teremos um melhor aluno na Unicamp. Um mecanismo de ação afirmativa que considera prioritariamente o mérito medido pelo vestibular pode na verdade melhorar o corpo discente da universidade (2006, p. 6).

A proposta original do programa consistia na adição de pontos à nota final do candidato, sendo 30 pontos para estudantes de escolas públicas e mais 10 pontos para os candidatos que se autodeclaram pretos, pardos ou indígenas. $\mathrm{O}$ programa passou por duas modificações importantes em sua configuração, em 2014 e 2016, mas a dinâmica geral de adição de pontos à nota dos candidatos foi mantida. Em 2014, a bonificação passou para 60 pontos e 20 pontos, respectivamente.

Apesar da bonificação, o percentual de ingressantes de EP aumentou de forma tímida entre 2005 e 2013, permanecendo na casa de 31\%, em média. Em 2014, com a primeira modificação, alcançou o percentual de $36,9 \%$, retornando no ano seguinte, entretanto, ao patamar de $30,2 \%$.

Na configuração atual, estabelecida para o vestibular de 2016, os estudantes que optam pelo Paais na inscrição recebem 60 pontos a mais na nota da primeira fase, e os candidatos autodeclarados PPI, 80 pontos. Além dos pontos adicionais na primeira fase, os candidatos recebem, cumulativamente, 90 pontos na nota final da redação e outros 90 pontos para as demais provas da segunda fase, ao passo que candidatos autodeclarados PPI recebem, além dos 90 pontos, outros 30, conforme descrito na Tabela 3. Essa modificação gerou um impacto expressivo no percentual de ingressantes pelo programa, alcançando o patamar de 47,6\% (UNICAMP, 2017). 
Tabela 3 - Modificações na pontuação do programa 2004, 2014 e 2016

\begin{tabular}{c|c|c|c|c}
\hline \multirow{2}{*}{ Ano } & \multicolumn{3}{|c}{ Adição de pontos vestibular } \\
\cline { 2 - 5 } & \multicolumn{2}{|c|}{$1^{\mathrm{a}}$ Fase } & \multicolumn{2}{c}{$2^{\mathrm{a}}$ Fase } \\
\cline { 2 - 5 } & $\begin{array}{c}\text { Escola } \\
\text { Pública }\end{array}$ & $\begin{array}{c}\text { Preto, } \\
\text { Pardo, } \\
\text { Indígena }\end{array}$ & $\begin{array}{c}\text { Escola } \\
\text { Pública }\end{array}$ & $\begin{array}{c}\text { Preto, Pardo, } \\
\text { Indígena }\end{array}$ \\
\hline 2004 & - & - & 30 & 40 \\
\hline 2014 & - & - & 60 & 80 \\
\hline 2016 & 60 & 80 & 90 & 120 \\
\hline
\end{tabular}

Fonte: elaboração própria com dados da Comvest (UNICAMP, 2017).

No período analisado, nota-se que o número de vagas disponibilizadas pela universidade cresceu. Em 2004, foram 2.810, e 3.320 em 2017, registrando-se, nesse período, a criação dos cursos da Faculdade de Ciências Aplicadas em Limeira: Ciências do Esporte, Engenharia de Manufatura, Engenharia de Produção, Gestão de Comércio Internacional, Gestão de Empresas, Gestão de Políticas Públicas, Gestão do Agronegócio e Nutrição. Com relação à evolução do número de matriculados provenientes de escolas públicas, em 2004, anteriormente à implementação do Paais, a quantidade de ingressantes foi de 806 estudantes, cerca de 28,3\%.

No vestibular de 2017, foram disponibilizadas 3.320 vagas, distribuídas entre as várias áreas do conhecimento. De acordo com as estatísticas divulgadas pela Comvest da Unicamp e representadas no Gráfico 1, do total de 3.248 matriculados, o número de alunos ingressantes pelo Paais atingiu, naquele ano, 50,3\% do total de ingressantes, totalizando 1.635 estudantes. Houve um crescimento de $73 \%$, se compararmos com o número de ingressantes pelo programa - 944 - em 2005, com destaque para um expressivo percentual de egressos de escolas públicas em cursos de maior concorrência, como Medicina, que alcançou um patamar histórico de 79\% de ingressantes pelo Paais. 


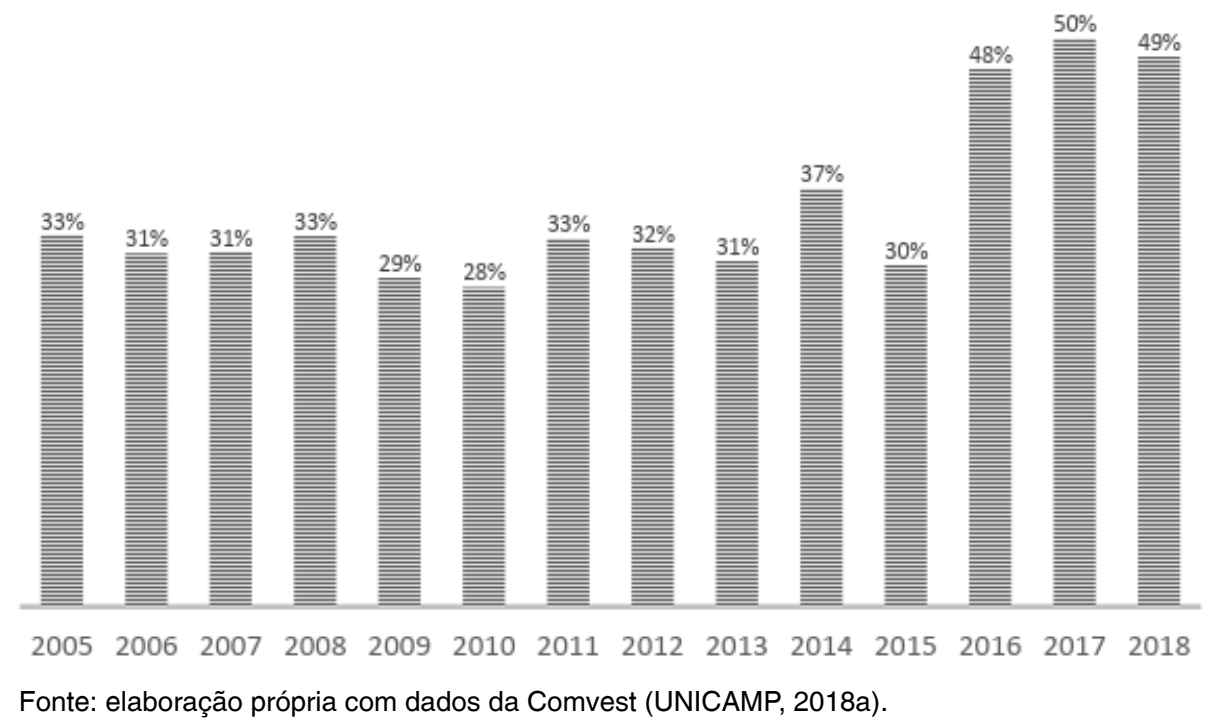

A política pública de inclusão implementada pela universidade aumentou o número de ingressantes provenientes de escolas públicas, em especial, a partir do vestibular de 2016. Dessa maneira, o intuito do presente trabalho é analisar, durante a vigência do Paais, qual o perfil geral dos ingressantes pelo programa, avaliando, assim, a dinâmica da política no processo de inclusão em razão do qual foi idealizada.

Avaliam-se os seguintes indicadores: alunos provenientes de escolas públicas (EP); composição racial em relação ao grupo autodeclarado preto, pardo ou indígena (PPI); tipo de estabelecimento onde cursou o ensino fundamental (EF); tipo de estabelecimento onde cursou o ensino médio (EM) - técnico (EMT), comum (EMC), outro; se frequentou curso pré-vestibular (PV); localidade de origem; e grau de instrução dos pais.

\section{Perfil dos ingressantes Paais (2005-2018)}

Inicia-se a análise a partir dos ingressantes que se autodeclaram PPI. No ano de 2004, o percentual de matriculados PPI foi de $12 \%$. Já em 2016, houve um expressivo crescimento, atingindo o percentual de $22 \%$. Em 2018, chegou-se a $24 \%$, de acordo com o Gráfico 2. Dentro do escopo dos matriculados ingressantes pelo Paais, o percentual de PPI é maior. Em 2005, na primeira seleção com a vigência 
da política, têm-se $26 \%$ de PPI, atingindo-se o montante de $34 \%$, em 2016 , e $35 \%$, em 2018. Dessa maneira, observa-se que, dentre os ingressantes pela política de inclusão da universidade, tem-se um percentual maior de ingressantes PPI, bem como se verifica que esse percentual cresceu entre 2005 e 2018.

O escopo da política de inclusão ora analisada apresenta um alinhamento com as políticas de inclusão que foram estabelecidas no país a partir dos anos 2000 . Entretanto, como citado anteriormente, o Paais é uma política de bonificação, sem reserva de vagas.

Em termos comparativos, o percentual da população brasileira de pretos e pardos (PP) é de 53\%, ao passo que, no estado de São Paulo, alcança 37\%, de acordo com dados do Instituto Brasileiro de Geografia e Estatística (2015). Dessa forma, a política da universidade, em termos totais, apesar da expansão, ainda não atingiu a representatividade da população brasileira PP.

\section{Gráfico 2 - Percentual de PPI com relação ao total de matriculados e em relação aos matriculados Paais}

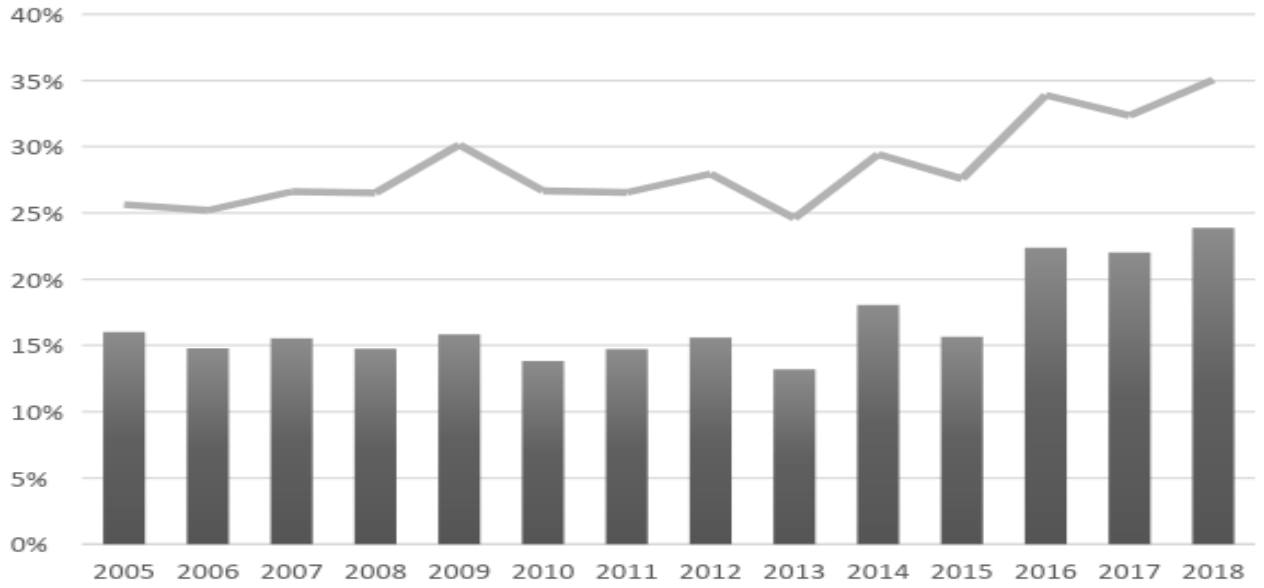

Fonte: elaboração própria com dados da Comvest (UNICAMP, 2018a).

Com relação ao total de ingressantes provenientes de escolas públicas (EP), núcleo da central de atuação do Paais, observa-se que, em 2013, o percentual foi de $31 \%$ do total de matriculados, e, em 2017 , chegou a $50 \%$, um crescimento de $62 \%$ no período. Esse resultado é semelhante ao obtido na investigação dos optantes pelo Paais, porém, apresenta uma pequena variação ao se comparar aos dados absolutos, considerando que o referido programa se apresenta como opção e, portanto, o candidato não é automaticamente inserido na bonificação.

Cabe relembrar que ocorreram duas modificações na configuração da bonificação do programa, sendo que a primeira, em 2014, levou a um aumento no per- 
centual de ingressantes EP para 37\%. No ano seguinte, houve uma redução desse percentual, que caiu para $30 \%$. Assim, em 2016, foi realizada uma nova modificação no programa, que acarretou no montante de $47 \%$, e, em 2017, atingiu seu ápice, com 50,2\% (UNICAMP, 2017).

A partir de 2016, o objetivo de proporcionar 50\% das vagas para os egressos das escolas públicas é atingido pelo programa, como pode ser observado no Gráfico 3. Assim, observa-se uma democratização no acesso à universidade, que, historicamente, recebeu $70 \%$ dos estudantes provenientes das escolas privadas, delineando-se, dessa forma, uma nova realidade, com a maior inserção de uma parcela da população antes excluída da Unicamp.

Gráfico 3 - Percentual de alunos matriculados provenientes de EP

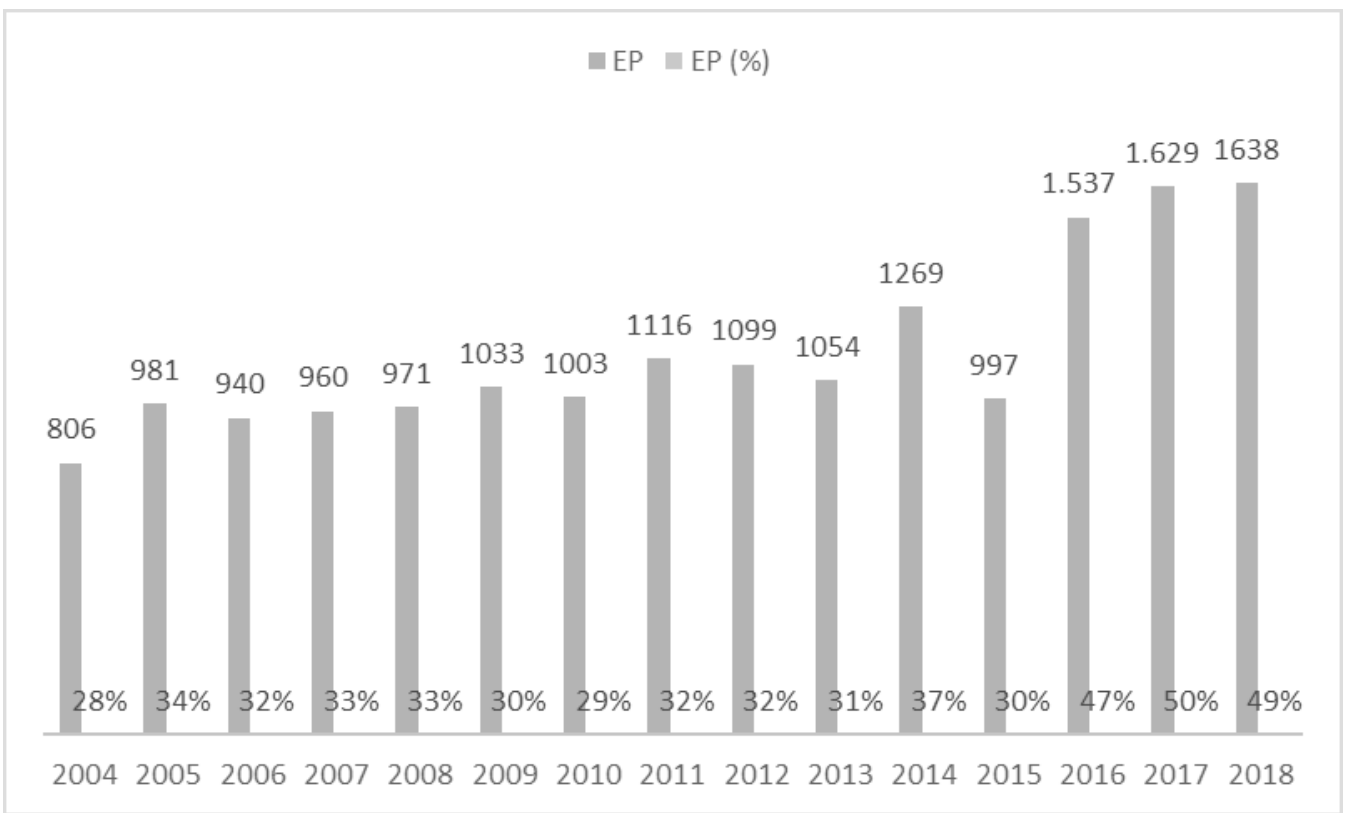

Fonte: elaboração própria com dados da Comvest (UNICAMP, 2018a).

Nota-se que a origem dos estudantes ingressantes na universidade por meio do Paais está concentrada no estado de São Paulo. Somando-se todas as regiões, o percentual é, em média, de $99 \%$ no período analisado, como se lê no Gráfico 4. Observam-se, no período, modificações na configuração, com relação à composição por região do estado. A Região Metropolitana de Campinas (RMC), por exemplo, tinha um percentual de 51\% em 2013, o qual se reduziu para 38\% em 2018. Com relação à Região Metropolitana de São Paulo (RMSP), observa-se uma oscilação positiva 
de 2013 (13\%) para 2018 (15\%). As demais regiões do estado, no geral, lograram crescimento, passando de $34 \%$ (2013) para $45 \%$ (2018).

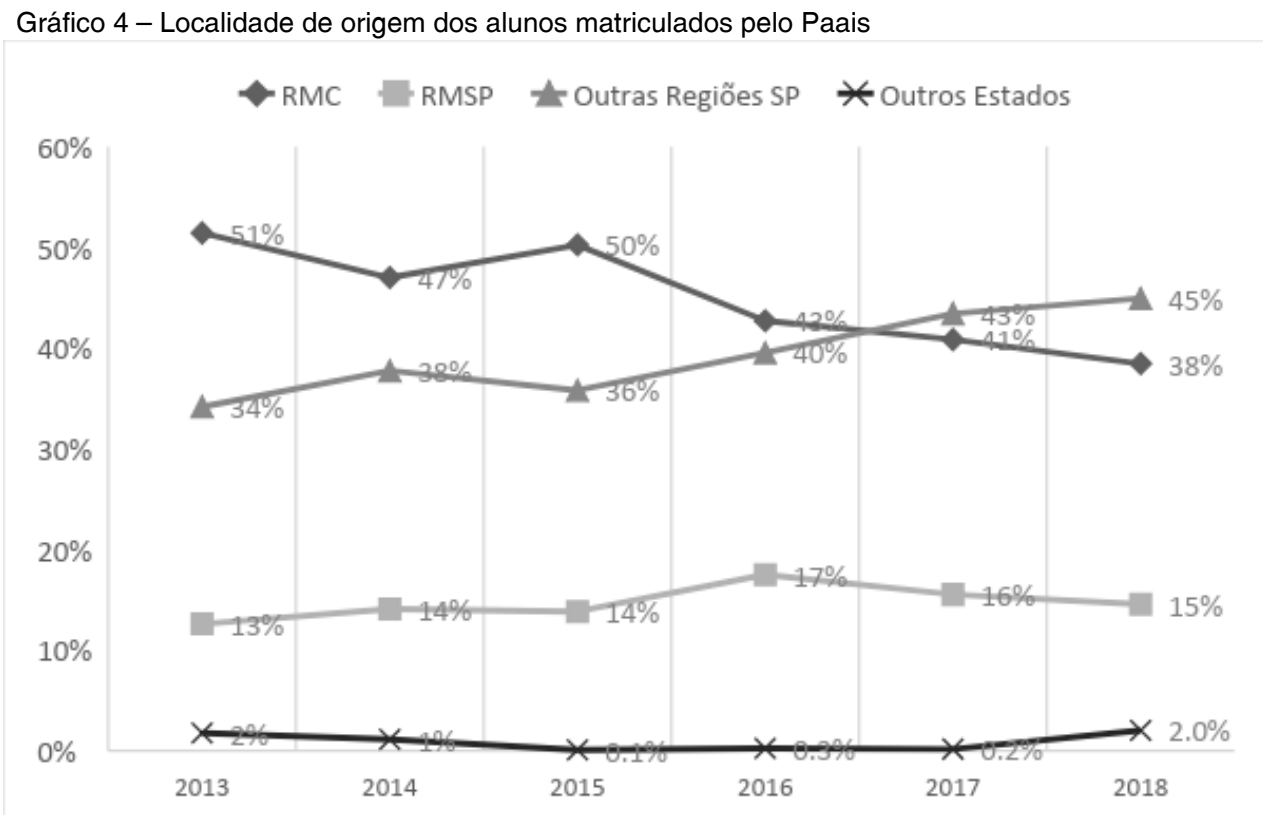

Fonte: elaboração própria com dados da Comvest (UNICAMP, 2018a).

Analisando a composição dos ingressantes que não são beneficiados pelo Paais, verifica-se que a configuração se manteve mais constante no período. Quanto à origem desses estudantes, em 2017, a distribuição se deu entre RMC (35\%), RMSP (22\%), outras regiões do estado (41\%) e outros estados (0,6\%), ficando, a exceção, por conta da queda expressiva no percentual de ingressantes de outros estados, que, em 2013, foi de $4 \%$ e, em $2018,2 \%$.

Esse fenômeno pode ser explicado pela maior oferta, nos anos 2000, de programas de inclusão no ensino superior pelo país, como o Prouni e o Fies, as cotas raciais e sociais, que podem influenciar na decisão dos futuros candidatos de optar por permanecerem em seus estados de origem.

Avaliando os recursos que a universidade disponibiliza para permanência estudantil, essa modificação na distribuição espacial da origem dos ingressantes pode ter refletido na demanda e, consequentemente, no montante de recursos investidos com o programa de bolsas de auxílio-moradia. De acordo com dados da Proposta de Distribuição Orçamentária da universidade, em 2013, foram destinados R $\$$ 
1.359.180, 00, correspondentes a 310 bolsas, já em 2018, o montante investido foi de $\mathrm{R} \$ 5.834 .568,00$, com 1.134 bolsas (UNICAMP, 2018b).

Além dos recursos com auxílio-moradia, que consiste em uma bolsa mensal de $\mathrm{R} \$ 428,76$, que atende a alunos de todos os campi - Campinas, Limeira (FT e FCA) e Piracicaba -, a universidade dispõe de 900 vagas na moradia estudantil, que atende apenas aos estudantes do campus de Campinas. A título de complementação dos dados, no período em questão não houve alteração na quantidade de vagas.

Em relação ao tipo de estabelecimento em que os ingressantes cursaram o ensino fundamental, nota-se, conforme exposto no Gráfico 5, um crescimento do percentual do ensino particular, que, em 2005, representava $16 \%$ e, em 2018, alcançou a casa dos 33\%. Cabe salientar que, a partir de 2017, a Comvest modificou a pergunta do questionário socioeconômico com relação ao ensino fundamental, incorporando a subdivisão em ensino fundamental 1 (EF1) ( $1^{\circ}$ ciclo $-1^{\circ}$ ao $5^{\circ}$ ano) e ensino fundamental 2 (EF2) ( $2^{\circ}$ ciclo - do $6^{\circ}$ ao $9^{\circ}$ ano), o que modificou a série de 2017 e 2018, destacando-se que, no caso do Gráfico 5, consideraram-se os percentuais do EF2.

Gráfico 5 - Tipo de estabelecimento de ensino fundamental dos matriculados pelo Paais

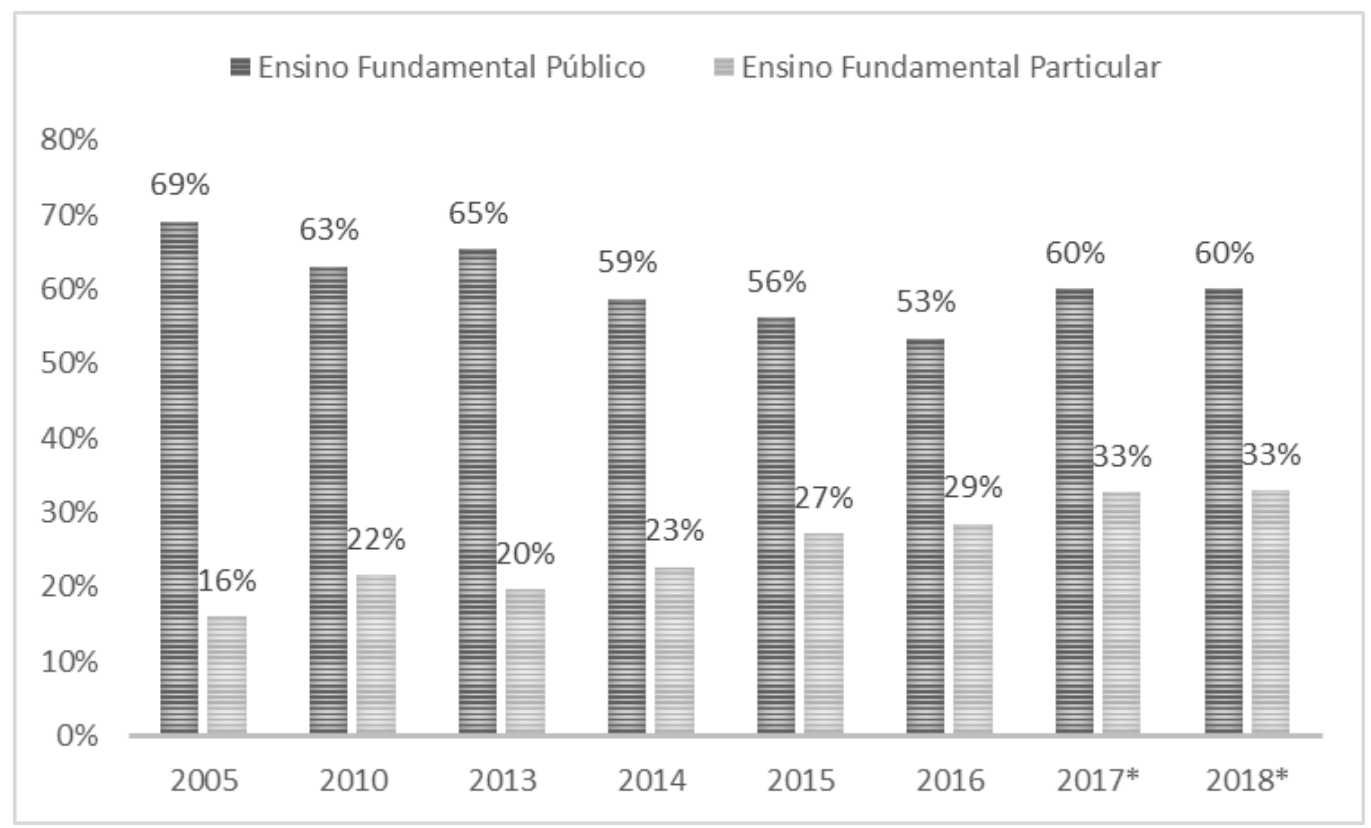

Fonte: elaboração própria com dados da Comvest (UNICAMP, 2018a). 
Dos índices relativos ao EF, deriva uma interessante nuance ensejada pelo programa. Em torno de 99\% dos beneficiados cursaram o ensino médio (EM) em estabelecimento público, o que demonstra uma considerável migração desses indivíduos do EF privado para o EM público, dado a ser analisado a seguir, no tocante ao tipo de curso realizado, elucidando alguns pontos desse perfil.

O perfil de curso realizado no ensino médio dos ingressantes pelo Paais tem se alterado de forma significativa. No primeiro ano do Paais, 2005, 60\% cursaram a modalidade do ensino médio comum (EMC), 34\% optaram pelo ensino médio técnico (EMT) e 5,3\% optaram por outras formas de conclusão do ensino médio (Enem, Educação de Jovens e Adultos, magistério e outros), conforme o Gráfico 6. Já em 2018, o número dos que realizaram EMC reduziu-se para 54\%, ao passo que os que fizeram EMT atingiram o percentual de $43 \%$, com um crescimento verificado de $26 \%$.

Gráfico 6 - Tipo de ensino médio cursado pelos alunos matriculados pelo Paais

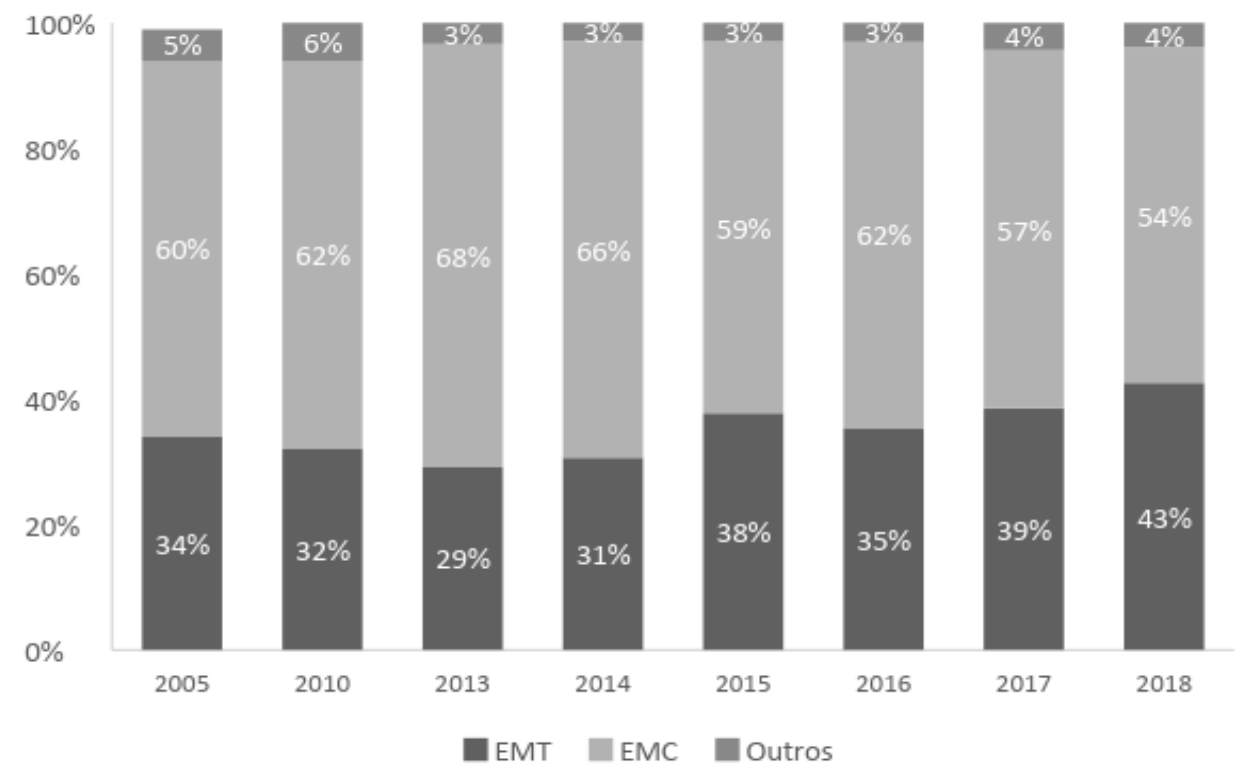

Fonte: elaboração própria com dados da Comvest (UNICAMP, 2018a).

Esse efeito precisa ser estudado de forma mais aprofundada, pois vários críticos do Paais compreendem que há uma distorção no programa, em virtude da hipótese de haver uma migração de estudantes que cursaram a rede particular no EF e, no EM, encaminharam-se a escolas técnicas públicas. Nas palavras de Tessler, 
Uma crítica frequente ao uso de escola pública como proxy para perfil socioeconômico é um suposto favorecimento aos estudantes de escolas públicas técnicas, que segundo os críticos teriam um perfil socioeconômico próximo ao dos egressos de escolas particulares (2006, p. 14).

A partir dos dados analisados, nota-se que há um crescimento do percentual de ingressantes do Paais que frequentaram estabelecimento de ensino privado no ensino fundamental, além do crescimento no número de ingressantes pelo programa que são egressos do EMT público.

Uma análise complementar com relação a esse tópico demonstra que, dos ingressantes não beneficiados pelo programa Paais, em 2017, apenas 3,7\% realizaram EMT, um dado que não se alterou de maneira representativa no período analisado.

Outro dado comparativo entre os ingressantes pelo Paais e os ingressantes sem o benefício, demonstrado no Gráfico 7, é a realização de curso pré-vestibular. Para as duas situações de ingresso, mais da metade dos estudantes frequentou algum tipo de curso nessa modalidade, em média, pelo período de um ano. Nessa comparação, os ingressantes pelo programa correspondem a um percentual maior em relação à formação pré-vestibular em 2018: pelo Paais, foram 59\%; sem o Paais, $55 \%$.

Gráfico 7 - Ingressantes que realizaram o curso pré-vestibular (Paais x sem Paais)

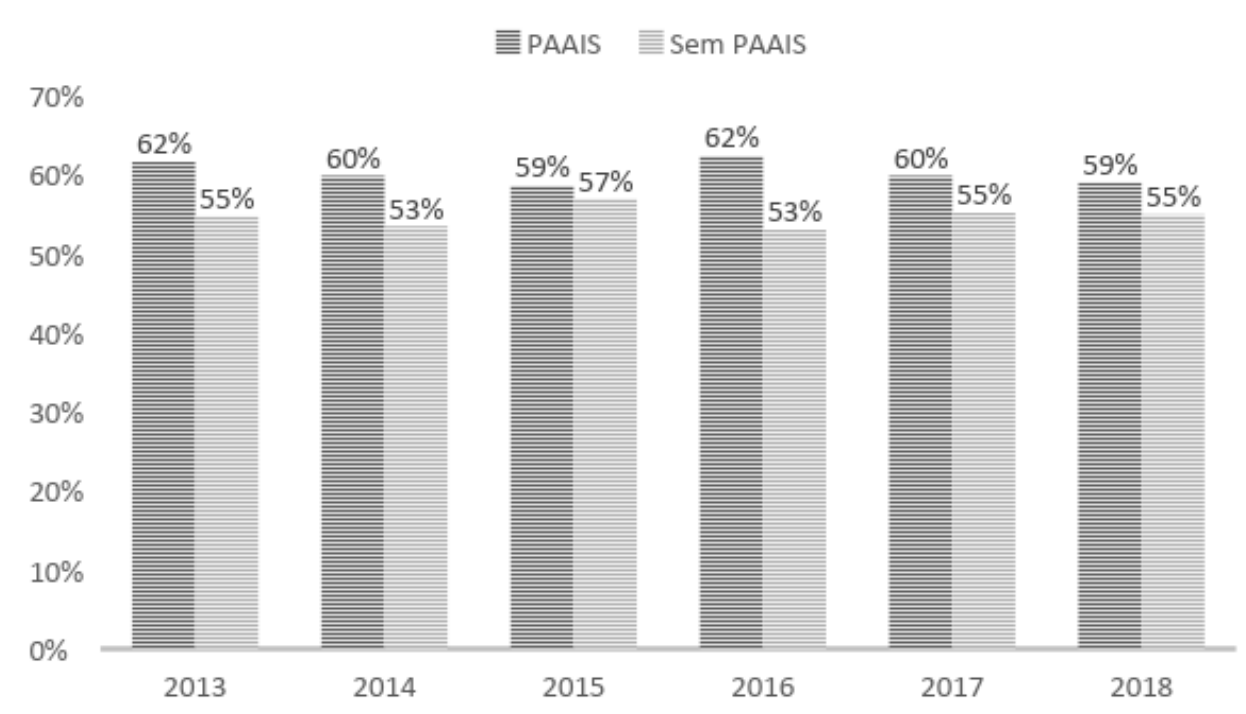

Fonte: elaboração própria com dados da Comvest (UNICAMP, 2017). 
Esse comparativo demonstra que há uma defasagem no ensino básico público, e os estudantes têm de realizar um período de estudos complementares em cursos pré-vestibular para conseguir competir por uma vaga em uma universidade pública como a Unicamp.

O último item dessa caracterização do perfil dos estudantes que ingressaram pelo Paais na universidade diz respeito ao nível de instrução de seus pais. Compreender a origem social dos estudantes auxilia na visualização do esforço empreendido para alcançar o ensino superior, uma vez que, de acordo com Bourdieu (2007), é determinante o papel da escola e dos sistemas educacionais nos processos de reprodução das desigualdades sociais, expressas no desempenho superior dos filhos das classes mais ricas nos exames escolares em contraposição ao dos filhos das classes mais pobres (BOURDIEU, 2007).

Pires (2015) aponta que os estudantes com renda maior e um dos pais com curso superior aumentam suas aspirações para o ensino superior público, uma vez que não demonstram muita motivação para ingressar no ensino superior privado. Para os mais pobres e com pais de menor escolaridade, embora exista o desejo de estudar no ensino superior público, "[...] o caminho mais 'natural' seria o de ingressar em instituições privadas, desde que possam contar com auxílios para o pagamento das mensalidades" (PIRES, 2015, p. 539).

Sendo assim, com relação ao nível de instrução dos pais de alunos ingressantes pelo Paais, nota-se que, em 2005, predominava o nível fundamental. ${ }^{1}$ No vestibular de 2018, analisando-se o Gráfico 8, constata-se que a faixa predominante é a de pais com formação até o ensino médio (2018 - 37\%), seguida pelas faixas com ensino superior (2018 - 26\%) e pós-graduação (2018 - 10\%). Ao comparar-se com os estudantes ingressantes sem a bonificação do Paais, há o predomínio de pais com ensino superior $(2018-43 \%)$ e pós-graduação $(2018-28 \%)$. 
Gráfico 8 - Grau de instrução dos pais dos ingressantes pelo Paais (\%)

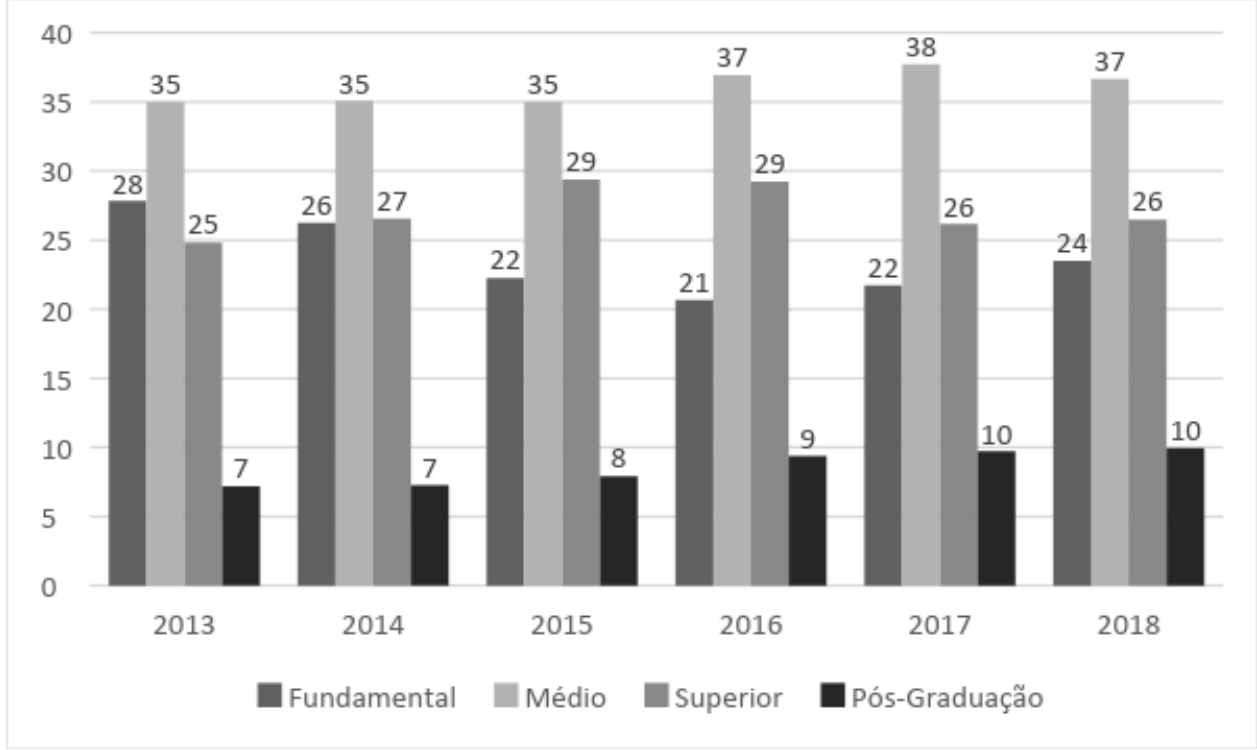

Fonte: elaboração própria com dados da Comvest (UNICAMP, 2017).

Com relação ao nível de instrução das mães de estudantes ingressantes pelo Paais, assim como na formação dos pais, houve modificação na configuração entre os níveis de estudos. Assim, em 2005, conforme o Gráfico 9, predominava o ensino fundamental, já em 2018, nota-se que a faixa predominante é de mães com formação até o ensino médio (2018 - 38\%), ensino superior em segundo lugar (2018 - 29\%) e, finalmente, pós-graduação $(2018-12 \%)$. No comparativo com as mães de ingressantes sem a bonificação do Paais, há o predomínio de mães com ensino superior $(2018-45 \%)$ e pós-graduação $(2018-28 \%)$.

Dessa forma, de acordo com Bourdieu (2007), a chance de acesso ao ensino superior está relacionada à origem dos indivíduos, ou seja, aqueles provenientes de famílias nas quais os pais tenham nível superior têm maiores chances de chegar ao ensino superior do que estudantes cujos pais tenham apenas o ensino fundamental ou médio. De acordo com os dados de escolaridade dos pais dos beneficiários dos Paais, é possível notar uma acentuada diferença na formação dos pais dos estudantes que não são ingressantes pelo programa. 
Gráfico 9 - Grau de instrução das mães de ingressantes pelo Paais (\%)

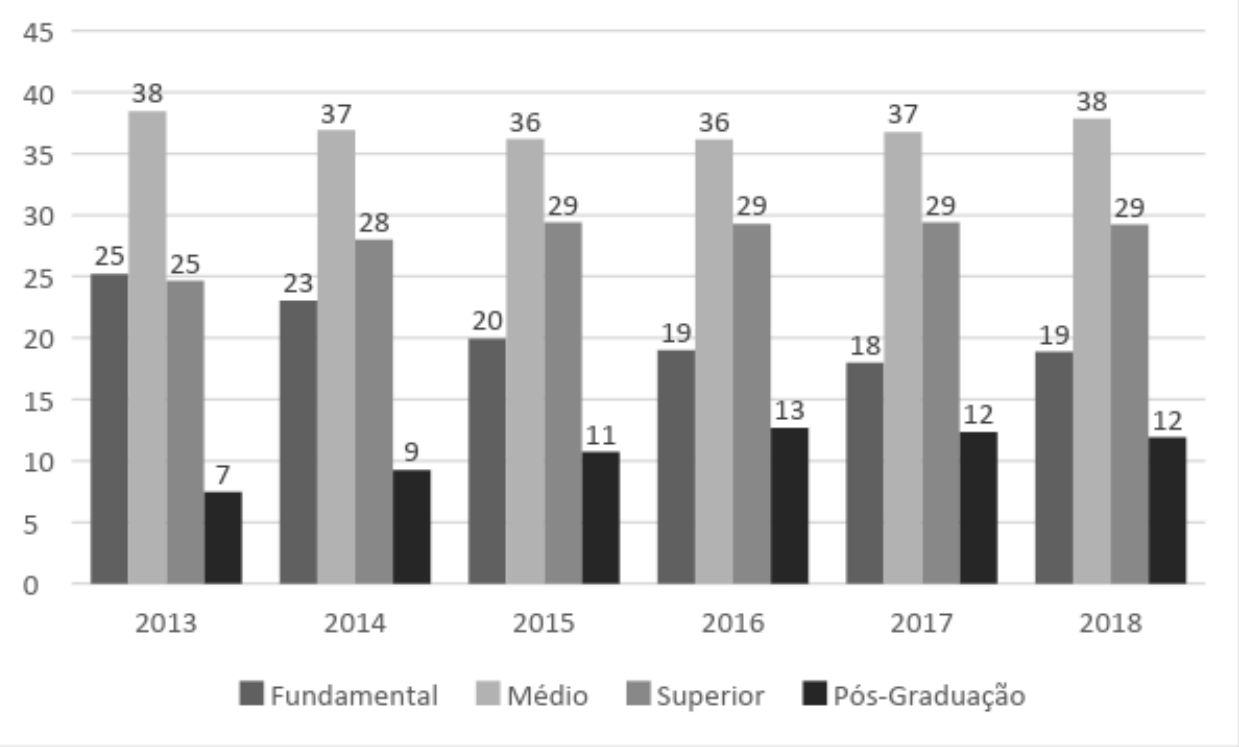

Fonte: elaboração própria com dados da Comvest (UNICAMP, 2017).

Há um predomínio de pais e mães com uma menor escolaridade entre os ingressantes pelo Paais, no entanto, no período analisado de 13 anos, o nível predominante deixou de ser o ensino fundamental e passou a ser o ensino médio. Mesmo assim, muitos dos estudantes ingressantes pelo programa provavelmente são a primeira geração a cursar o ensino superior em suas famílias, o que demonstra uma modificação em termos de sua progressão social e de seu capital escolar.

\section{Perspectivas de modificação na política de inclusão para 2019}

Aprovada pelo Conselho Universitário da Unicamp em maio de 2017, a Deliberação do Conselho Universitário no 8 , de 2017, determina o ingresso por meio de cotas raciais. A partir dessa aprovação, foi designado o grupo de trabalho denominado GT-Ingresso, responsável pela formulação da proposta de implementação das cotas raciais na universidade a partir do vestibular de 2019 .

O relatório elaborado pelo grupo de trabalho e as discussões nas várias unidades de ensino da universidade delinearam o novo formato de ingresso na universidade, que determina que $70 \%$ das vagas serão distribuídas por meio do vestibular, $20 \%$ serão atribuídas mediante comparação das notas do Enem, em edital específico, e $10 \%$ serão destinadas a alunos com desempenho diferenciado em olimpíadas 
científicas e congêneres, vestibular indígena e Programa de Formação Interdisciplinar, nos termos da Deliberação CONSU 32/2017:

Artigo $1^{\circ}$ - A Universidade Estadual de Campinas utilizará diferentes sistemas de ingresso a seus cursos de graduação, com regras específicas em cada um dos sistemas, nos seguintes termos:

I - Vestibular Unicamp, por meio do qual serão oferecidas, no mínimo, $70 \%$ das vagas regulares;

II - Edital utilizando as notas do Exame Nacional do Ensino Médio (Enem), por meio do qual serão oferecidas até $20 \%$ das vagas regulares;

III - Seleção de alunos a partir do desempenho em olimpíadas científicas, competições de conhecimento ou outras modalidades que demonstrem desempenho excepcional do estudante a critério de áreas específicas, limitado ao máximo de 10\% total de vagas regulares; IV - Vestibular Indígena, específico para os povos indígenas;

V - Programa de Formação Interdisciplinar Superior (ProFIS), criado pela Deliberação Consu 409/2010, com oferecimento de vagas adicionais.

$\S 1^{\circ}$ - Será adotada reserva de vagas para optantes por cotas étnico-raciais, que incidirá sobre a oferta das vagas indicadas nos incisos I e II deste artigo.

$\S 2^{\circ}$ - Anualmente a Universidade divulgará o número de vagas destinadas a cada um desses sistemas de ingresso aos seus cursos de graduação (UNICAMP, 2017, p. 01).

Com relação às cotas étnico-raciais, serão reservados $25 \%$ do total de vagas para pretos e pardos, distribuídos em $10 \%$ no edital do Enem e 15\% no vestibular geral. As cotas contemplarão todos os cursos e turnos oferecidos pela universidade.

O Paais passará por uma nova modificação, que pontuará de forma diferenciada estudantes que cursaram os ensinos fundamental e médio em estabelecimentos públicos, considerando a seguinte bonificação:

I - Adição, na primeira fase, de 40 (quarenta) pontos à Nota Padronizada da primeira fase (NPF1) de candidatos ao Vestibular Unicamp que tenham cursado integralmente o Ensino Médio em escolas da rede pública, comprovado mediante documento oficial dos estabelecimentos de ensino. Caso tenha sido aprovado para a segunda fase, serão acrescidos 40 (quarenta) pontos à Nota Padronizada de redação (NPR) e 40 (quarenta) pontos à Nota Padronizada das provas dissertativas (NPF2);

II - Adição, na primeira fase, de 20 (vinte) pontos à Nota Padronizada da primeira fase (NPF1) de candidatos ao Vestibular Unicamp que tenham cursado integralmente o Ensino Fundamental II em escolas da rede pública, comprovado mediante documento oficial dos estabelecimentos de ensino. Caso tenha sido aprovado para a segunda fase, serão acrescidos 20 (vinte) pontos à Nota Padronizada de redação (NPR) e 20 (vinte) pontos à Nota Padronizada das provas dissertativas (NPF2) (UNICAMP, 2017, p. 02).

As medidas estabelecidas pelo Conselho Universitário da Unicamp entrarão em vigor a partir do vestibular de 2019. Quanto aos percentuais definidos para as cotas, será procedida à reavaliação anual, com o intuito de atingir o percentual de $37 \%$ de PP, correspondente ao percentual da população do estado de São Paulo que se autodeclara preta ou parda. 


\section{Considerações finais}

O presente texto analisou as políticas de inclusão da Unicamp e avaliou o perfil dos estudantes que foram beneficiados pelos referidos programas. O Paais, a mais antiga dessas políticas, tem mais de dez anos e passou por duas modificações importantes para os vestibulares de 2014 e 2016, alcançando, em sua atual configuração, um percentual de 50\% de ingressantes oriundos de EP, o que se equipara com a política nacional estabelecida pelo governo federal de disponibilizar $50 \%$ das vagas para estudantes da rede pública.

Durante os 13 anos de existência do Paais, podem-se dividir os resultados do programa em dois períodos. Primeiro, de 2005 a 2013, período em que os resultados, com relação ao aumento do número de ingressantes vindos de escolas públicas e de estudantes autodeclarados PPI, foram muito tímidos, em especial, pelo fato de a bonificação ser disponibilizada apenas na segunda fase do vestibular, o que já demonstra uma barreira para os estudantes de escolas públicas perante os estudantes de escolas privadas. A partir da modificação realizada em 2015 e vigente a partir do vestibular 2016, os candidatos EP e PPI passaram a receber a bonificação nas duas fases, atingindo o percentual de 50\% de ingressantes pelo Paais em 2017 e, praticamente, mantendo esse resultado em 2018, com $35 \%$ das vagas destinadas a PPI, o que representa $24 \%$ do total de matriculados.

A universidade, a partir de 2019, passará a operacionalizar uma nova política de inclusão, abrangendo também a reserva de vagas a partir das cotas raciais, uma nova modificação no Paais, seleção pelas notas do Enem, expansão das vagas do ProFIS, seleção por vestibular indígena e por desempenho em olimpíadas científicas.

Dessa maneira, a proposta de modificação da política de inclusão expressa o propósito de aumentar a inclusão na universidade, aventando, ainda, que, avaliar e monitorar os resultados do vestibular de 2019 poderá trazer novas respostas sobre a efetividade das políticas em foco.

\section{Nota}

1 No questionário da Comvest, constam as opções de ensinos fundamental, médio, superior e pós-graduação completo e incompleto; para fins deste estudo, computaram-se, em cada nível, as opções completo e incompleto. 


\section{Referências}

ALMEIDA, Ana Maria F.; ERNICA, Mauricio. Inclusão e segmentação social no ensino superior público no estado de São Paulo (1990-2012). Educação e Sociedade, Campinas, v. 36, n. 130, p. 63-83, 2015. Disponível em: <http://dx.doi.org/10.1590/ES0101-73302015139672>. Acesso em: 1 set. 2018.

ALPHONSE, Fritznel. Análise do Programa de Ação Afirmativa e Inclusão Social (PAAIS) implementado pela Unicamp no período de 2005-2014. 2015. 379 f. Dissertação (Mestrado em Educação) - Faculdade de Educação, Universidade Estadual de Campinas, Campinas, 2015. Disponível em: <http://www.bibliotecadigital.unicamp.br/document/?code=000948614>. Acesso em: 2 set. 2017.

ANDRADE, Cibele Yahn. Acesso ao ensino superior no Brasil: equidade e desigualdade social. Revista de Ensino Superior, Campinas, SP, n. 6, p. 18-27, 2012. Disponível em: <https://www. revistaensinosuperior.gr.unicamp.br/artigos/acesso-ao-ensino-superior-no-brasil-equidade-e-desigualdade-social>. Acesso em: 10 set. 2017.

BOURDIEU, Pierre. A escola conservadora: as desigualdades frente à escola e à cultura. In: NOGUEIRA, Maria Alice; CATANI, Afrânio (Org.). Escritos de educação. 9. ed. Petrópolis, RJ: Vozes, 2007. p. 39-64.

BRASIL. Decreto n⿳ำ 5.493, de 18 de julho de 2005. Programa Universidade para todos (Prouni), Brasília, DF, 2005. Disponível em: <http://www.planalto.gov.br/ccivil_03/_ato2004-2006/2005/decreto/d5493.htm>. Acesso em: 29 ago. 2017.

Decreto $\mathrm{n}^{\mathrm{o}}$ 7.824, de 11 de outubro de 2012. Regulamentação de Cotas. Brasília, DF, 2012a. Disponível em: <http://www.planalto.gov.br/ccivil_03/_ato2011-2014/2012/decreto/D7824. htm>. Acesso em: 29 ago. 2017.

Decreto $\mathrm{n}^{\mathrm{o}} 7.790$, de 15 de agosto de 2012. Fundo de Financiamento Estudantil (Fies). Brasília, DF, 2012b. Disponível em: <http://www.planalto.gov.br/ccivil_03/_ato2011-2014/2012/ decreto/d7790.htm>. Acesso em: 29 ago. 2017.

Lei $\mathrm{n}^{\circ} 5.540$, de 28 de novembro de 1968. Fixa normas de organização e funcionamento do ensino superior e sua articulação com a escola média. Brasília, DF, 1968. Disponível em: <https:// www.planalto.gov.br/ccivil_03/leis/15540.htm>. Acesso em: 29 dez. 2017.

. Ministério da Educação. Número de brasileiros com graduação cresce em 10 anos. 2012c. Disponível em: <http://portal.mec.gov.br/ultimas-noticias/212-educacao-superior-1690610854/17725-numero-de-brasileiros-com-graduacao-cresce-10983-em-10-anos $>$. Acesso em: 28 set. 2017.

Ministério da Educação. Censo Ensino Superior. Brasília, DF: Inep/MEC, 2016. Disponível em: <http://portal.inep.gov.br/censo-da-educacao-superior>. Acesso em: 28 set. 2017.

Programa Universidade para Todos. O programa. Brasília, DF, 2018. Disponível em: $<$ http://prouniportal.mec.gov.br/o-programa>. Acesso em: 05 maio 2018.

DURHAM, Eunice Ribeiro. Uma política para o ensino superior brasileiro: diagnóstico e proposta. São Paulo: Núcleo de Pesquisas sobre Ensino Superior; Universidade de São Paulo, 1998. 
DURHAM, Eunice Ribeiro; GOLDEMBERG, J. Uma política para o ensino superior. São Paulo: Núcleo de Pesquisas sobre Ensino Superior; Universidade de São Paulo, 1993.

HERINGER, Rosana. Um balanço de 10 anos de políticas de ação afirmativa no Brasil. Tomo, Aracajú, SE, n. 24, p. 17-35, 2014. Disponível em: <http://dx.doi.org/10.21669/tomo.v0i0.3184>. Acesso em: 19 nov. 2018.

INSTITUTO BRASILEIRO DE GEOGRAFIA E ESTATÍSTICA. Pesquisa Nacional por Amostra de Domicílios (PNAD). Rio de Janeiro: IBGE, 2015.

SAMPAIO, Helena. O ensino superior no Brasil: o setor privado. São Paulo: Fapesp/ Hucitec, 2000.

MARCONI, Marina de Andrade; LAKATOS, Eva Maria. Fundamentos da metodologia científica. 5. ed. São Paulo: Atlas, 2003.

MARTINS, Carlos Benedito. A reforma universitária de 1968 e a abertura para o ensino superior privado no Brasil. Educação e Sociedade, Campinas, v. 30, n. 106, p. 15-35, 2009. Disponível em: <http://dx.doi.org/10.1590/S0101-73302009000100002>. Acesso em: 29 jun. 2018.

ORGANIZAÇÃO PARA COOPERAÇÃO E DESENVOLVIMENTO ECONÔMICO. Education at a Glance. 2016. Disponível em: <http://www.oecd-ilibrary.org/docserver/download/9616041e. pdf? expires $=1509315696 \& i d=i d \& a c c n a m e=$ guest $\&$ checksum $=$ C5EE45677182B 47 AC $879 A 90$ 9D1603895>. Acesso em: 20 ago. 2017.

OLIVEIRA, Laércio Rodrigues. As repercussões do acordo com o FMI sobre os ajustes da economia brasileira. Pesquisa \& Debate, São Paulo, v. 17, n. 1 (29), p. 79-102, 2006.

PIRES, André. Renda familiar e escolaridade dos pais: reflexões a partir dos microdados do Enem 2012 do estado de São Paulo. Educação Temática Digital, Campinas, SP, v. 17, n. 3, nov. 2015. Disponível em: <http://periodicos.sbu.unicamp.br/ojs/index.php/etd/article/view/8638262>. Acesso em: $15 \mathrm{dez} .2015$.

RISTOFF, Dilvo. Democratização do campus: impactos dos programas de inclusão sobre o perfil da graduação. Cadernos do GEA, Rio de Janeiro: FLACSO, GEA, Uerj, LPP, n. 9, 2012-v, jan./ jun. 2016.

SCHWARTZMAN, Simon. Demanda e políticas públicas para o ensino superior nos BRICS. Caderno CRH, Salvador, v. 28, n. 74, p. 267-290, ago. 2015 Disponível em: <http://www.scielo.br/ scielo.php?script=sci_arttext\&pid=S0103-49792015000200267\&lng=en\&nrm=iso $>$. Acesso em: 03 dez. 2017.

SCHOFER, Evan; MEYER, John W. The World-Wide Expansion of Higher Education. Center on Democracy, Development, and The Rule of Law. Stanford Institute on International Studies, Stanford, n. 32, January 20, 2005.

UNIVERSIDADE ESTADUAL DE CAMPINAS. Comissão Permanente para o Vestibular (Comvest). 2018a. Disponível em: <http://www.comvest.unicamp.br/inclusao-paais/>. Acesso em: 29 jun. 2018.

Deliberação CONSU no 12/2004. Estabelece o Programa de Ação Afirmativa para Inclusão Social na Unicamp. 2004. Disponível em: <https://www.pg.unicamp.br/mostra_norma. php?consolidada=S\&id_norma=2786>. Acesso em: 22 fev. 2018. 
. Deliberação CONSU no 32/2017. Dispõe sobre os programas de ingresso nos cursos de graduação da Unicamp. 2017. Disponível em: <http://www.pg.unicamp.br/mostra_norma. php?id_norma=10240>. Acesso em: 22 fev. 2018.

. Assessoria de Economia e Planejamento. Proposta de Distribuição Orçamentária. 2018b. Disponível em: <https://www.aeplan.unicamp.br/proposta_orcamentaria/unicamp/pdo_unicamp_2018.pdf>. Acesso em: 22 fev. 2018.

VELLOSO, Jacques. Curso e concurso: rendimento na universidade e desempenho em um vestibular com cotas da UnB. Brasília: UnB, 2006. Disponível em: <http://www.observa.ifcs.ufrj.br/ relatorios/Cursoeconcurso_UnB.pdf>. Acesso em: 25 set. 2017

Cotistas e não-cotistas: rendimento de alunos da Universidade de Brasília. Cadernos de Pesquisa, São Paulo, v. 39, n. 137, p. 621-644, maio/ago. 2009.

TESSLER, Leandro R. Ação afirmativa sem cotas: o Programa de Ação Afirmativa e Inclusão Social da Unicamp. Campinas: Unicamp, 2006. Disponível em: <http://www.comvest.unicamp. br/wp-content/uploads/2017/02/artigo1.pdf>. Acesso em: 22 set. 2017.

TESSLER, Leandro; PEDROSA, Renato. Paais: a experiência de um programa de ação afirmativa na Unicamp. Revista Movimento em Debate, Campinas, ano 1, n. 2, dez. 2008. Disponível em: <http://flacso.redelivre.org.br/files/2012/07/23.pdf>. Acesso em: 22 set. 2017.

WAINER, Jacques; MELGUIZO, Tatiana. Políticas de inclusão no ensino superior: avaliação do desempenho dos alunos baseado no Enade de 2012 a 2014. Educação e Pesquisa, São Paulo, v. 44, p. 1-15, 2018. Disponível em: <http://www.scielo.br/scielo.php?script=sci_arttext\&pid=S1517 $7022017005001103 \& l n g=$ pt\&nrm=iso $>$. Acesso em: 03 dez. 2017. 